\title{
[Title Page]
}

\section{Article title}

\author{
Effects of High-dose Intravenous Vitamin C on Point-of-Care Blood Glucose Level \\ in Septic Patients: A Retrospective, Single-Center, Observational Case Series
}

\section{Authors' information}

Juan $\mathrm{He}^{1}$, Guanhao Zheng ${ }^{2 \#}$, Xian Qian ${ }^{3}$, Huiqiu Sheng ${ }^{4}$, Bing Chen $^{1}$, Bing Zhao ${ }^{*}$, Erzhen Chen ${ }^{* 4}$, Enqiang Mao ${ }^{* 4}$, Xiaolan Bian ${ }^{* 1}$

1: Department of Pharmacy, Shanghai JiaoTong University Medical School Affiliated Ruijin Hospital, Shanghai, China;

2: Department of Pharmacy, Shenzhen Hospital, Southern Medical University, Shenzhen, China;

3: Department of Pharmacy, Shanghai Eastern Hepatobiliary Surgery Hospital, Shanghai, China;

4: Department of Emergency Intensive Care Unit, Shanghai JiaoTong University Medical School Affiliated Ruijin Hospital, Shanghai, China.

\footnotetext{
\#: co-first author.

*: Correspondence should be addressed to Prof. Xiaolan Bian, Department of Pharmacy, Ruijin Hospital Affiliated to Shanghai JiaoTong University School of Medicine, 3 Floor, 12 building, 197 Ruijin No.2 Road, Huangpu District, Shanghai, China, E-mail: bx170029@163.com.

": Correspondence may also be addressed to Prof. Erzhen Chen, EICU of Ruijin Hospital Affiliated to Shanghai JiaoTong University School of Medicine. 3 Floor, 5 building, 197 Ruijin No.2 Road, Huangpu District, Shanghai, China, E-mail: chenerzhen@ hotmail.com, and Dr. Bing Zhao, EICU of Ruijin Hospital Affiliated to Shanghai JiaoTong University School of Medicine. 3 Floor, 5 building, 197 Ruijin No.2 Road, Huangpu District, Shanghai, China, E-mail: zhaobing124@163.com. And Prof. Prof. Enqiang Mao, EICU of Ruijin Hospital Affiliated to Shanghai JiaoTong University School of Medicine. 3 Floor, 5 building, 197 Ruijin No.2 Road, Huangpu District, Shanghai, China, E-mail: maoeq@yeah.net.

NOTE: This preprint reports new research that has not been certified by peer review and should not be used to guide clinical practice.
} 


\begin{abstract}
Introduction: High-dose vitamin $\mathrm{C}$ (hdVC) is regarded as one of the essential adjunctive drugs for sepsis treatment. The present study aimed to deduce if hdVC could lead to erroneous testing results from the point-of-care glucose (POCG) measurement.

Methods and materials: This retrospective, single-center, observational case series involved septic patients treated by hdVC and monitored their paired POCG and laboratory glucose (LG) level for statistical analysis. The Parkes Consensus Error Grid Analysis was used as clinical influence assessment for paired blood glucose values. Subgroup analyses were conducted to explore the affecting extent of POCG readings by different $\mathrm{VC}$ dosage and various renal function level respectively.

Results: During the 3-year research period, 82 eligible septic patients who accepted at least three-day hdVC treatment were included in the current study. Compliance with ISO15197:2013 criteria was met in $30(36.59 \%)$ paired values, which was far from the minimum criteria for accuracy. Subgroup analysis showed that worse renal function or higher VC dosage could lead to greater bias of POCG reading, but clinical risk would come forth scarcely while dealing with inaccurate POCG value.

Conclusions: High-dose intravenous ascorbate acid infusion could interfere POCG measurement values and LG method is more recommended, although significant medical risk hardly appears when physicians alter clinical action based on unreliable POCG reading.
\end{abstract}

Keywords: vitamin C, point-of-care, glucose, sepsis.

Short title: Effect of vitamin C on point-of-care blood glucose 


\section{Introduction}

Sepsis is a highly lethal clinical condition with systemic and inflammatory response to infection which could give rise to hemodynamic abnormality and multiple organ dysfunction syndrome (MODS)[1]. The basic treatment of sepsis includes anti-infectious treatment, source control, appropriate fluid resuscitation for maintenance of hemodynamic stability, as well as vasopressors[2]. Since ascorbic acid deficiency is widely observed and associated with rising morbidity in critically ill patients, high-dose vitamin $\mathrm{C}(\mathrm{VC})$ is regarded as one of the essential adjunctive therapies for treating sepsis because of its cost-efficiency and necessity[3]. Potential mechanisms of VC in sepsis treatment include amelioration of excessive oxidative stress and enhancement of cellular immune function $[1,4,5]$. The high-dose intravenous $\mathrm{VC}$ is considered to be a safe treatment, while only a few case reports have described the $\mathrm{VC}$-associated calcium oxalate nephropathy as the primary adverse effect $[2,6]$.

As frequent blood glucose monitoring is essential to maintain normoglycemia for septic patients in intensive care unit (ICU) [7], controversy about hdVC interference of POCG measurement could not be neglected clinically. Erroneous blood glucose reading could cause clinical overtreatment about false hyperglycemia or hypoglycemia, which may bring on serious medical risk. Therefore, the current study focused on confirming whether hdVC could lead to erroneous testing results from POCG measurement as compared to the referential laboratory venous LG level measurement. The secondary aim of this study was to establish the correlation between different dosages of $\mathrm{VC}$ and the affected extent of POCG measurement level. Moreover, since elimination of VC in vivo mainly depends on glomerulus filtration and renal tubular reabsorption by sodiumdependent vitamin $\mathrm{C}$ transporter $1[8,9]$, which may indicate $\mathrm{VC}$ is excreted by kidney

principally, researchers of this study want to find out if renal function could be another key factor to affect the POCG result.

\section{Methods and materials}


This retrospective, single-center, observational case series was conducted at the Emergency intensive care unit in Ruijin Hospital affiliated to Medical School of Shanghai Jiao Tong University, China. Because of the observational, non-interventional design, the inclusion of patients started after approval of the study by Ruijin Hospital Institutional Review Board and performed in accordance with the ethical standards of the Declaration of Helsinki 1964 and its later amendments or comparable ethical standards. VC was used for adjunctive therapy of sepsis in emergency intensive care unit (EICU) since 2013. The eligibility criteria of patients were as follows: (1) Age $\geq 18$ years; (2) EICU admission between January 2016 and December 2019; (3) Fulfilled the standard classification of The Third International Consensus Definitions for Sepsis with SOFA score $\geq 2$ within the initial $24 \mathrm{~h}$ of admission[10]; (4) Treated by hdVC with corresponding dosage regimen for at least 3 days without using insulin, acetaminophen, mannitol and dopamine during hdVC treatment.

Patients who met the standard criteria were placed on hdVC infusion with corresponding dosage which depends on their severity of sepsis. In the current study, daily dosage of $\mathrm{VC}$ was between $50 \mathrm{mg} / \mathrm{kg}$ to $200 \mathrm{mg} / \mathrm{kg}$. The constant infusion rate at 1 $\mathrm{g} / \mathrm{h}$ of $\mathrm{VC}$ was applied in all patients. Time of starting infusion is daily fixed at $9 \mathrm{am}$. Dosage was not adjusted during continuous renal replacement therapy (CRRT). The duration of $\mathrm{VC}$ therapy lasted for at least 3 days and was dependent on the progression of the patient's illness.

To verify the accuracy of POCG measurement, patients in this study underwent paired POCG and LG simultaneous measurements in two points of time as 15 minutes before first dose hdVC infusion and a quarter after last dose hdVC infusion, respectively. Time between paired POCG and LG blood sample collection were controlled within 15 minutes. POCG testing was performed by Medisafe mini blood glucose meter (Terumo Corporation, Tokyo, Japan) using the glucose oxidase-peroxidase (GOD-POD) colorimetric method. The laboratory LG measurements were carried out by Beckman Coulter AU5800 Chemistry Analyzer (Beckman Coulter Inc., S. Kraemer Boulevard, CA, USA) using a hexokinase spectrophotometric method. The source of the blood sample was not recorded. 
Baseline data and clinical information, including age, sex, height, weight, Acute Physiology and Chronic Health Evaluation (APACHE) II scores, Systemic Inflammatory Response Syndrome (SIRS) scores, history of diabetes mellitus, serum creatinine level, CRRT modes (if paired blood glucose collection was in CRRT therapy period), POCG level, laboratory LG level and clinical outcomes were recorded by the researchers when each patient was on admission within 24 hours. SIRS scores were defined as 4 criteria: (1) fever ( $>38.0 \square$ ) or hypothermia ( $<36.0 \square)$; (2) tachycardia (heart rate $>90$ beats/min); (3) tachypnea (respiratory rate $>20$ breaths/min); (4) leukocytosis, leukopenia, or bandemia (white blood cells $>1,200 / \mathrm{mm}^{3},<4,000 / \mathrm{mm}^{3}$ or bandemia $\geq 10 \%$ ). Each criterion owned 1 score and Patients who got at least two scores were considered as occurrence of SIRS[11, 12]. The hemoglobin level and hematocrit (HCT) was also recorded when hdVC usage was begun. Continuous data was recorded as median (interquartile range, IQR) values.

The primary endpoint of current study was to evaluate the accuracy of paired POCG and LG reading as well as the clinical significance of differences among paired POCG and LG results during the hdVC infusion period. Difference of paired POCG and LG results were calculated based on the Relative Difference Percentage $(\%)=[\mathrm{POCG}]-$ $[\mathrm{LG}] /[\mathrm{LG}] \times 100 \%)$ between POCG and LG results.

Wilcoxon's matched pairs test was performed to find out if there were significant differences between POCG and LG readings before and after the hdVC treatment period by SPSS (IBM® SPSS® Statistics v26.0.0.0, Chicago, IL, USA). The comparison of relative difference percentage before and after the hdVC treatment period were analyzed with the Kruskal-Wallis test by SPSS as well. The data was expressed as mean \pm standard deviation. P-values $<0.05$ was considered as statistically significant.

When it comes to the clinical impact of unreliable POCG result during hdVC infusion period, only paired blood glucose samples collected after hdVC treatment were included in analysis of this step. ISO15197:2013 criteria[13] was performed as judging standard. As for the compliance of the criteria, at least $95 \%$ of POCG result need to be in range of $\pm 15 \mathrm{mg} / \mathrm{dl}$ when referential blood glucose result is less than $100 \mathrm{mg} / \mathrm{dl}$, or within $\pm 15 \%$ of the LG result if the blood glucose level is no less than $100 \mathrm{mg} / \mathrm{dl}[14]$. Bland-Altman method was utilized to further investigate the measurement of agreement 
among all paired POCG and LG results by GraphPad Prism Version 8.3.0 (538)[15]. The Parkes Consensus Error Grid Analysis, which was operated by Blood Glucose Monitoring System Surveillance Program[16], was aimed to assess the clinical significance of difference[17]. This error grid was divided into 5 zones which symbolized corresponding degree of risk associated with inaccurate measurement results. Zone A meant difference had no effect on clinical action. Zone B represented altering clinical action that could change little or no effect on clinical outcome. Zone $\mathrm{C}$ signified altering clinical action that could be likely to affect clinical outcome. Zone D was known as altering clinical action that could cause significant medical risk and Zone E defined clinical actions that could have dangerous consequences.

Secondary endpoints are the accuracy of POCG measurement in patients based on different dosages and renal function. In our study, all patients were divided in two groups by dosage levels. Patients with higher dosage were administered VC from over $100 \mathrm{mg} / \mathrm{kg}$ to $200 \mathrm{mg} / \mathrm{kg}$ per day, while patients with lower dosage were daily treated by $\mathrm{VC}$ from $50 \mathrm{mg} / \mathrm{kg}$ to no more than $100 \mathrm{mg} / \mathrm{kg}$. Categorization was carried out according to patients' renal function as well. Paired blood glucose collection from patients with an increased creatinine clearance of greater than $130 \mathrm{~mL} / \mathrm{min} / 1.73 \mathrm{~m}^{2}$ on admission was classified as 'Augment Renal Clearance (ARC)'. Paired blood glucose acquired and measured when patients underwent CRRT treatment was determined as 'CRRT'. Patients who had a history of Chronic Kidney Diseases (CKD) or blood serum creatinine $\geq 150 \%$ patients' baseline serum creatinine within 24-hour admission period defined as impaired renal function[18]. Correspondingly, non-impaired renal function was identified as patients' blood serum creatinine $\leq 150 \%$ baseline serum creatinine within 24-hour admission period and lack of a history of CKD. Baseline serum creatinine was derived from patient's personal electronic medical record. Creatinine level on admission was also considered as baseline serum creatinine only when patients' baseline serum creatinine was lack of adequate information in their medical record.

\section{Results}


From January 2016 to December 2019, 656 patients were consecutively admitted to the EICU in the hospital. Among 141 potentially eligible septic patients treated by hdVC during this period, 59 were excluded (10 patients' age were under 18, 27 had insulin administration in the VC therapy period, 16 were treated with VC less than $72 \mathrm{~h}$, and 24 used dopamine as concomitant medication) and $82(58.16 \%)$ fulfilled the criteria for inclusion in the present study (Table 1).

Concomitant medication was a major influencing factor of POCG testing. Acetaminophen, dopamine, and mannitol might affect the POCG reading results, especially for dosage-dependent false-positive interference with glucose measurements by dopamine[19]. Insulin could cause blood glucose sharply dropping in a very short time. Therefore, patients who accepted acetaminophen, dopamine, mannitol and insulin treatment were excluded for reducing interference of the current study.

Furthermore, HCT interference was another crucial factor of POCG accuracy. The hematocrit range of 35 to $60 \%$ was considered as a reliable range for minimizing measuring bias [20,21]. All 82 patients in the current study met this criterion and no one was excluded from the research.

The 82 patients displayed 14 (IQR 12-20) and 3 (IQR 2-3) for APACHE II score and SIRS score, respectively. Approximately, $18 \%$ of patients presented a medical history of diabetes mellitus. The median serum creatinine level of all patients was 82.5 (IQR 63-149.25). The hemoglobin level was recorded as median $114 \mathrm{~g} / \mathrm{L}$ (IQR 85-136.5). Moreover, 15 patients (18.29\%) had accepted CRRT during VC therapy period (mostly Continuous Veno-Venous Hemodiafiltration (CVVHDF) mode for 10 patients), and 16 patients (19.51\%) had varying degrees of impaired kidney function. Normal kidney function and ARC accounted for $42(51.22 \%)$ and 9 (10.98\%) patients, respectively. Despite the positive and effective treatment in EICU, 16 patients succumbed to various kinds of refractory pathogenesis eventually and 9 patients were transferred out from EICU with exacerbating condition. Five patients cured totally from their own illness and 52 patients got recovered gradually. The median number of $\mathrm{VC}$ dosage was $100 \mathrm{mg} /(\mathrm{kg} \cdot \mathrm{d})$ (IQR 74.99-133.33) and VC therapy duration was 9 days (IQR 6-15). 35 (42.68\%) 
patients were accepted higher dosage treatment and $47(57.32 \%)$ patients were taken lower dosage therapy.

For all patients, POCG value was significantly lower than LG reading whether before hdVC infusion $(158.08 \pm 62.08 \mathrm{mg} / \mathrm{dl}$ vs $186.25 \pm 71.50 \mathrm{mg} / \mathrm{dl}, P<0.001$, Table 2) or after hdVC treatment $(142.90 \pm 58.91 \mathrm{mg} / \mathrm{dl}$ vs $186.74 \pm 72.74 \mathrm{mg} / \mathrm{dl}, P<0.001$, Table 2). Relative difference percentages from paired blood glucose of patients who had finished hdVC treatment were significantly higher than those of patients who had not started hdVC infusion(-17.86\% $\pm 35.68 \%$ vs $-12.43 \% \pm 21.44 \%, P=0.01$, Table 2$)$, which implied that infusion of hdVC could increase the differences between POCG and LG values indeed.

The accuracy of POCG reading measurements compared to LG reading measurements was only $36.59 \%$ (Table 3), which indicated a failure to meet the minimum 95\% accuracy standard following the compliance with ISO 15197:2013 criteria. The Bland-Altman plot (Figure 1) presented that mean difference between POCG and LG result was $-43.83 \mathrm{mg} / \mathrm{dl}$. The mean POCG values were obviously lower than mean LG readings with $95 \%$ limits of agreement of -177.97 and $90.32 \mathrm{mg} / \mathrm{dl}$. The Parkes Consensus Error Grid Analysis (Figure 2) of POCG variation showed that difference of 2 $(2.44 \%)$ paired blood glucose could induce a significant medical risk when altering clinical action. However, little clinical impact of POCG differences was exhibited under most circumstance since $42(51.22 \%)$ paired blood glucose results fell into Zone A in the Parkes consensus error grid analysis, Zone B and Zone C owned 19 (23.17\%) paired samples equally as well.

Dosage classification for paired blood glucose level with the compliance of ISO 15197:2013 criteria was detailed in Table 4. Forty-seven paired blood glucose values collected as lower dosage and only 18 (38.30\%) pairs followed ISO 15197:2013 criteria. Compliance with ISO 15197:2013 criteria was met in 12 (34.29\%) paired POCG and LG results of 35 evaluated as paired blood glucose collection of higher dosage. The Parkes Consensus Error Grid Analysis showed that $76.6 \%$ and $71.42 \%$ blood glucose pairs from lower and higher dosage group fell into Zone A and Zone B respectively, while 5.71\% blood glucose pairs from higher dosage caused inaccurate POCG measurement results 
that could significantly affect clinical outcome. No Paired blood glucose result from lower dosage group included in Zone D and Zone E (Table 5).

Furthermore, renal function was another key stratified factor for all paired blood glucose collection in this research. There were 42 patients with non-impaired renal function. Nineteen (45.24\%) of them provided paired blood glucose readings in compliance with ISO 15197:2013 criteria. Six (37.5\%) paired blood glucose values among 16 paired blood glucose measurement from patients with impaired renal function met the criteria. With regards to the rate of compliance about aforementioned criteria, only $22.22 \%$ and $20 \%$ for CRRT and ARC patients respectively (Table 6). Table 7 exhibited the result of Parkes Consensus Error Grid Analysis for each renal function level. Blood sample pairs from patients with non-impaired renal function (78.58\%) or augment renal clearance $(88.89 \%$ ) had higher possibility to categorize in Zone A and Zone B than those from patients with impaired renal function (68.75\%) or suffering CRRT treatment (60\%). In addition, both impaired renal function and CRRT group owned one paired blood sample which fell into Zone D.

\section{Discussion}

Clinically, drug interference of POCG value would lead to the inappropriate therapy for fictitious hyperglycemia or hypoglycemia[22]. Improper treatment with hypoglycemic agents for fictitious hyperglycemia could bring about a series of clinical symptoms like trembling, heart racing, nausea and sweating, even coma or death in some severe cases[23]. False low POCG reading might induce practitioners using high concentration of glucose supplement for patients, which could elevate blood glucose level above normal value. High blood glucose status usually accompanied with higher risk of infection, even increased mortality rates for septic patients[24].

High dose ascorbic acid causing inaccurate POCG reading is widely concerned clinically these years. According to the retrospective review by Kahn et al., 18 burn shock patients were administered hdVC $(66 \mathrm{mg} / \mathrm{kg} / \mathrm{h} \times 18 \mathrm{~h})$ infusions during burn resuscitation; 5 were chosen for the subsequent analysis. High-dose VC infusion for burn 
shock would give rise to fictitious hyperglycemia for POCG measurement as compared to the LG measurement result [25]. Sartor et al. designed another case series for the direct comparison of POCG and LG values in 7 patients with $>30 \%$ burns on the total body surface area (TBSA); these patients received $66 \mathrm{mg} / \mathrm{kg} / \mathrm{h}$ VC treatment. The study found that POCG level was elevated during the infusion period in all the patients [26]. Conversely, a prospective observational pilot study was designed by Smith et al., wherein 5 patients were administered $\mathrm{VC}$ at $1.5 \mathrm{~g} \mathrm{q} 6 \mathrm{~h} / \mathrm{d}$, which did not lead to clinically significant differences between POCG and LG results [27].

Therefore, this study aimed to explore if high dose ascorbate acid infusion could cause fictitious value according to the POCG results as compared to the LG measurement. Moreover, the secondary target was to verify whether $\mathrm{VC}$ dosages or kidney function are the putative influencing factors with falsely readings of POCG.

In our research, statistical bias was detected about the measurement results from POCG using the GOD-POD method. There was a significant lower value for POCG compared to paired LG result after hdVC infusion. Statistically significant augmentation of relative difference percentages between POCG and LG reading was observed in period of hdVC post-infusion as well. This might imply that POCG measurement is unreliable when hdVC is used as adjunctive therapy, which suggested avoiding POCG as the blood glucose measurement when patients use hdVC treatment, besides LG is strongly recommended as the alternative ideal blood glucose monitoring method instead of POCG measurement.

A rational explanation of this phenomenon was that different methods were applied in POCG and LG testing, respectively. The GOD-POD colorimetric method is employed for POCG testing while the hexokinase method is for LG measurement.

The hexokinase spectrophotometric method is specific for measuring glucose in the serum or plasma (Figure 3a). Initially, hexokinase plus adenosine triphosphate (ATP) transforms glucose to glucose-6-phosphate (G-6-P) plus adenosine diphosphate (ADP), followed by a reaction started by G-6-P, NAD ${ }^{+}$, and G-6-P dehydrogenase to generate $\mathrm{NADH}$, which is measured spectrophotometrically at $340 \mathrm{~nm}$. NADH is proportional to 
the glucose level, and no interaction was observed between NADH and ascorbic acid. VC did not interfere with the results of the hexokinase method [25].

GOD-POD colorimetric method is a convenient way of determining the level of glucose. GOD catalyzes the oxidation of glucose to gluconate, and hydrogen peroxide $\left(\mathrm{H}_{2} \mathrm{O}_{2}\right)$ is liberated, which reacts with phenol and 4-aminophenazone (4-AP) in the presence of POD to form red quinonimine dye. The intensity of color was measured colorimetrically at $530 \mathrm{~nm}$, which is directly proportional to the concentration of glucose in plasma [28, 29]. $\mathrm{VC}$ is a strong reductant and may set off redox reaction with $\mathrm{H}_{2} \mathrm{O}_{2}$, indicating that the depletion of $\mathrm{H}_{2} \mathrm{O}_{2}$ lowers the reading of POCG, which is consistent with the present research result (Figure 3b)[30].

Interestingly, our study exhibited a controversial result that POCG reading was lower than referential LG value. It was opposite to other researches while they showed incorrect POCG result could cause fictitious hyperglycemia by clinical measurement[25, $27,31]$. We found that other studies used glucose dehydrogenase pyrroloquinoline quinone (GDH-PQQ) amperometric method as POCG measurement method, which was different from GOD-POD colorimetric method by mechanism[25, 27, 31]. Nicotinamide adenine dinucleotide (NAD) is converted to NADH while Glucose is catalyzed to Dglucose-delta lactone by glucose dehydrogenase. NADH acts as an electron donor to create a mensurable electrical charge which could be quantified by an electrode (Figure $3 c)$. Therefore, glucose level from blood sample is proportional to the sum of electron produced. As a strong reductant, $\mathrm{VC}$ is also an excellent electron donor which is oxidized at the electrode and release extra electrons to interfere the measurement result[25]. And that's why fictitious hyperglycemia shows up when blood glucose measurement carries out by GDH-PQQ method in hdVC infusion period. This may indicate that higher or lower POCG erroneous reading may depend on various measuring methods when using hdVC as treatment. Since GDH-PPQ methods was widely utilized by plenty of blood glucose monitoring devices in Chinese hospitals, Fictitious lower POCG readings could become a potential medical risk induced by clinical application of hdVC diffusely.

Compliance with ISO15197:2013 criteria existed only 36.59\% among all paired blood glucose values, which was far below the minimum accuracy criteria (95\%). This 
also signified a great difference of compliance with ISO15197:2013 criteria among Smith $(81.3 \%)$ and Howell's researches $(73.9 \%)$ respectively[27, 31]. Clinical influence of POCG value measuring interference by hdVC infusion was assessed by Parkes Consensus Error Grid Analysis in present study as well. Only 2.44\% POCG value bias could cause significant medical risk when altering clinical action. In other words, inaccurate POCG reading by hdVC treatment could barely have a significant clinical effect in most situation.

According to some other researches, higher serum ascorbic acid concentration could be more likely to cause incorrect POCG reading[25, 26, 32, 33]. It depends on its daily dosage and renal excretion in vivo to a great extent. For further exploration, subgroup analysis was conducted to confirm if VC dosage or diverse level of patients' renal function could be concernful affecting factors of erroneous POCG reading.

Although there is a consistency that more than $3 \mathrm{~g}$ daily dosage of $\mathrm{VC}$ supplement is needed to maintain the normal serum normal serum vitamin C levels[34] and improve the clinical outcomes for severe ill patients[35, 36], the optimal dosage of VC as adjunctive treatment for sepsis is still unclear. Fowler et al finished a phase I trial for intravenous $\mathrm{VC}$ in 2014 . Low dose $(50 \mathrm{mg} / \mathrm{kg} / 24 \mathrm{~h})$ and high dose $(200 \mathrm{mg} / \mathrm{kg} / 24 \mathrm{~h})$ were adopted for patients with severe sepsis every 6 hours[37]. Marik et al administered VC intravenously with $1.5 \mathrm{~g}$ q6h with thiamine and hydrocortisone as the treatment of severe sepsis and septic shock[38]. Recently, the CITRIS-ALI Randomized Clinical Trial took $50 \mathrm{mg} / \mathrm{kg}$ VC infusing every 6 hours for 4 days as treatment protocol[39]. With augmentation in serum VC concentration, POCG results may have a higher possibility to show an inaccurate reading. Hence, for the sake of verifying the extent of POCG reading interference by different VC dosage, we defined $50 \mathrm{mg} / \mathrm{kg} / 24 \mathrm{~h}$ to $100 \mathrm{mg} / \mathrm{kg} / 24 \mathrm{~h}$ as low dosage and $100 \mathrm{mg} / \mathrm{kg} / 24 \mathrm{~h}$ to $200 \mathrm{mg} / \mathrm{kg} / 24 \mathrm{~h}$ as high dosage respectively. Continuous infusion was adopted for maintaining more stable serum VC concentration to minimize bias as well. In the current study, higher VC dosage could induce POCG measurement bias easier than lower VC dosage. Significant medical risk could be more likely to generate in higher dosage group when altering clinical action in terms of erroneous POCG reading, compared to lower dosage group. It seems that higher dosage VC 
infusion could be more likely to induce unfaithful POCG measurement result. However, irrefutable conclusion could not be made due to the inadequate sample size of this research and lack of serum VC concentration monitoring, which should be taken into consideration in our further investigation.

Various levels of renal function for septic patients may also play an important role in excretion of $\mathrm{VC}$ in vivo due to its highly water-solubility and urinary elimination $[8,9]$. Howell et al found that kidney function did not appeal to have a clinical impact on inaccurate POCG readings, but vasopressor administration interference was not excluded and patients with augmented renal clearance were not included in their research[31]. In terms of the Parkes Consensus Error Grid Analysis result in our study, there was an obviously larger difference between POCG and LG reading for patients who underwent CRRT treatment or suffered from impaired renal function. What's more, significant clinical risk could not emerge when dealing with incorrect POCG value for patients with non-impaired renal function or augmented renal clearance, while $6.25 \%$ and $6.67 \%$ patients might have medical risk in impaired renal function and CRRT group respectively. Therefore, we could draw a conclusion that worse kidney function would cause POCG reading inaccuracy to greater extent. This fact is consistent with our hypothesis, which may be elaborated by VC accumulation in vivo due to decreasing renal elimination of VC. Similarly, affirmation could also not be made firmly because of uncertainty of VC serum concentration as well as comparatively small sample size.

The present study had some limitations. Firstly, it was a retrospective, single-center, observational case series with a small number of patients. Multiple-center prospective evaluation or randomized control trial (RCT) with a larger sample size should be put into practice. In addition to the GOD-POD method, other POCG measurement tools, such as glucose-dehydrogenase-pyrroloquinoline quinone (GOD-PQQ) amperometry method, were also available [25]. Taken together, further experiments along with other POCG measurement methods as replenishment are essential. As for the design of this study, it may be confused that researchers acquired blood glucose samples for paired measurement after hdVC infusion instead of during infusion period. On the one hand, since personalized hdVC treating protocols carried out as daily constant infusion with 
various dosages and days for different patients, researchers obtained blood samples after VC infusion for steady serum concentration uniformly. On the other hand, the 1.87-hour half-life time of intravenous VC in vivo owned minor effects when we got paired blood samples for measurement in 15 minutes after VC infusion[40]. Further researches should set up with a fixed treatment period and getting blood glucose samples during infusion time for contrast. Ascorbic acid concentration should be monitored as well. Another limitation for this research was lack of exclusion about other chemicals which could interfere accuracy of POCG measurement, such as glutathione, heparin, ibuprofen, etc[14]. Last but not the least, it is also important to ensure duration of hdVC treatment and monitor serum VC concentration during hdVC infusion period in future study.

\section{Conclusions}

In summary, POCG measurement could be interfered by high-dose intravenous ascorbate acid infusion as compared to the reference LG method indeed. Although significant medical influence barely come up when altering clinical action by unreliable POCG reading, the LG method should be recommended to adopt for its accuracy. Moreover, elevating the dosage of VC would alter the POCG reading results to some extent. Renal function may also be another important affecting factor as well. Further investigations such as RCTs or prospective trials should be put into practice to verify the results of the current study.

\section{Transparency}

\section{Declaration of Funding}

This study was supported by Shanghai Shen Kang Hospital Development Center Clinical Science and technology innovation project (No. SHDC12017116) and Important and weak discipline construction plan for health and family planning system of Shanghai (No. 2016ZB0206).

\section{Declaration of financial/other relationships}


All authors declared no financial or other relationships in this study should be declared in this paper.

\section{Author contributions}

GZ, JH and XB had full access to all data in the study and take responsibility for the integrity and the accuracy of the data analysis; they contributed equally to the manuscript. GZ, JH and XB conceived and designed this study, participated in study design and coordination, and helped to draft the manuscript. GZ, JH, XQ, BZ, HS, XB, BC, EC and EM collected the information, and contributed to the acquisition, analysis and interpretation of the data. GZ, JH and $\mathrm{XB}$ wrote and revised the manuscript. All authors read and approved the final manuscript.

\section{Acknowledgements}

The authors thank the staff of the EICU Department of Ruijin Hospital affiliated to Medical School of Shanghai Jiao Tong University for their facilities and collaboration.

\section{References}

1. Badeaux JE, Martin JB. Emerging Adjunctive Approach for the Treatment of Sepsis: Vitamin $C$ and Thiamine. Critical care nursing clinics of North America. 2018 Sep;30(3):343-351. doi: 10.1016/j.cnc.2018.05.002. PubMed PMID: 30098738; eng.

2. Kuhn SO, Meissner K, Mayes LM, et al. Vitamin C in sepsis. Current opinion in anaesthesiology. 2018 Feb;31(1):55-60. doi: 10.1097/aco.0000000000000549. PubMed PMID: 29176375; PubMed Central PMCID: PMCPMC5996765. eng.

3. Carr AC, Shaw GM, Fowler AA, et al. Ascorbate-dependent vasopressor synthesis: a rationale for vitamin $C$ administration in severe sepsis and septic shock? Crit Care. 2015 Nov 27;19:418. doi: 10.1186/s13054-015-1131-2. PubMed PMID: 26612352; PubMed Central PMCID: PMCPMC4661979.

4. Du WD, Yuan ZR, Sun J, et al. Therapeutic efficacy of high-dose vitamin C on acute pancreatitis and its potential mechanisms. World Journal of Gastroenterology. 2003;9(11):2565-2569.

5. Berger MM, Oudemans-van Straaten HM. Vitamin C supplementation in the critically ill patient. Current opinion in clinical nutrition and metabolic care. 2015 Mar;18(2):193201. doi: 10.1097/mco.0000000000000148. PubMed PMID: 25635594; eng.

6. Wilson JX. Evaluation of vitamin C for adjuvant sepsis therapy. Antioxidants \& Redox Signaling. 2013;19(17):2129-2140.

7. Rhodes A, Evans LE, Alhazzani W, et al. Surviving Sepsis Campaign: International Guidelines for Management of Sepsis and Septic Shock: 2016. Intensive care medicine. 
2017 Mar;43(3):304-377. doi: 10.1007/s00134-017-4683-6. PubMed PMID: 28101605; eng.

8. Levine M, Padayatty SJ, Espey MG. Vitamin C: a concentration-function approach yields pharmacology and therapeutic discoveries. Advances in nutrition (Bethesda, Md). 2011 Mar;2(2):78-88. doi: 10.3945/an.110.000109. PubMed PMID: 22332036; PubMed Central PMCID: PMCPMC3065766 interest. eng.

9. Duconge J, Miranda-Massari JR, Gonzalez MJ, et al. Pharmacokinetics of vitamin C: insights into the oral and intravenous administration of ascorbate. Puerto Rico health sciences journal. 2008 Mar;27(1):7-19. PubMed PMID: 18450228; eng.

10. Singer M, Deutschman CS, Seymour CW, et al. The Third International Consensus Definitions for Sepsis and Septic Shock (Sepsis-3). Jama. 2016 Feb 23;315(8):801-10. doi: 10.1001/jama.2016.0287. PubMed PMID: 26903338; PubMed Central PMCID: PMCPMC4968574. eng.

11. Bone RC, Balk RA, Cerra FB, et al. Definitions for sepsis and organ failure and guidelines for the use of innovative therapies in sepsis. The ACCP/SCCM Consensus Conference Committee. American College of Chest Physicians/Society of Critical Care Medicine. Chest. 1992 Jun;101(6):1644-55. doi: 10.1378/chest.101.6.1644. PubMed PMID: 1303622; eng.

12. Marik PE, Taeb AM. SIRS, qSOFA and new sepsis definition. Journal of thoracic disease. 2017 Apr;9(4):943-945. doi: 10.21037/jtd.2017.03.125. PubMed PMID: 28523143; PubMed Central PMCID: PMCPMC5418298. eng.

13. Jendrike N, Baumstark A, Kamecke U, et al. ISO 15197: 2013 Evaluation of a Blood Glucose Monitoring System's Measurement Accuracy. Journal of diabetes science and technology. 2017 Nov;11(6):1275-1276. doi: 10.1177/1932296817727550. PubMed PMID: 28849677; PubMed Central PMCID: PMCPMC5951056. eng.

14. ISO 15197:2013 In vitro diagnostic test systems - Requirements for blood-glucose monitoring systems for self-testing in managing diabetes mellitus [September 9th, 2019]. Available from: https://www.iso.org/standard/54976.html

15. Bland JM, Altman DG. Measuring agreement in method comparison studies. Statistical methods in medical research. 1999 Jun;8(2):135-60. doi: 10.1177/096228029900800204. PubMed PMID: 10501650; eng.

16. Blood Glucose Monitoring System Surveillance Program [September 9th, 2019]. Available from: https://www.diabetestechnology.org/seg/

17. Parkes JL, Slatin SL, Pardo S, et al. A new consensus error grid to evaluate the clinical significance of inaccuracies in the measurement of blood glucose. Diabetes care. 2000 Aug;23(8):1143-8. doi: 10.2337/diacare.23.8.1143. PubMed PMID: 10937512; eng.

18. Kellum JA, Lameire N. Diagnosis, evaluation, and management of acute kidney injury: a KDIGO summary (Part 1). Critical care (London, England). 2013 Feb 4;17(1):204. doi: 10.1186/cc11454. PubMed PMID: 23394211; PubMed Central PMCID: PMCPMC4057151. eng.

19. Tang Z, Du X, Louie RF, et al. Effects of drugs on glucose measurements with handheld glucose meters and a portable glucose analyzer. American journal of clinical pathology. 2000 Jan;113(1):75-86. doi: 10.1309/qaw1-x5xw-bvrq-5lkq. PubMed PMID: 10631860; eng.

20. Ramljak S, Lock JP, Schipper C, et al. Hematocrit interference of blood glucose meters for patient self-measurement. Journal of diabetes science and technology. $2013 \mathrm{Jan}$ 1;7(1):179-89. doi: 10.1177/193229681300700123. PubMed PMID: 23439176; PubMed Central PMCID: PMCPMC3692232. eng. 
21. Hattemer A, Wardat S. Evaluation of Hematocrit Influence on Self-Monitoring of Blood Glucose Based on ISO 15197:2013: Comparison of a Novel System With Five Systems With Different Hematocrit Ranges. Journal of diabetes science and technology. 2018 Mar;12(2):333-340. doi: 10.1177/1932296818757550. PubMed PMID: 29374966; PubMed Central PMCID: PMCPMC5851235. eng.

22. Vasudevan S, Hirsch IB. Interference of intravenous vitamin $\mathrm{C}$ with blood glucose testing. Diabetes care. 2014;37(5):e93-4. doi: 10.2337/dc13-2452. PubMed PMID: 24757251; eng.

23. Tomky DJDS. Detection, prevention, and treatment of hypoglycemia in the hospital. 2005;18(1):39-44.

24. Schuetz $P$, Castro $P$, Shapiro NI. Diabetes and sepsis: preclinical findings and clinical relevance. Diabetes care. 2011 Mar;34(3):771-8. doi: 10.2337/dc10-1185. PubMed PMID: 21357364; PubMed Central PMCID: PMCPMC3041224. eng.

25. Kahn SA, Lentz CW. Fictitious hyperglycemia: point-of-care glucose measurement is inaccurate during high-dose vitamin $\mathrm{C}$ infusion for burn shock resuscitation. J Burn Care Res. 2015 Mar-Apr;36(2):e67-71. doi: 10.1097/BCR.0000000000000141. PubMed PMID: 25162951.

26. Sartor Z, Kesey J, Dissanaike S. The effects of intravenous vitamin C on point-of-care glucose monitoring. Journal of burn care $\&$ research : official publication of the American Burn Association. 2015 Jan-Feb;36(1):50-6. doi: 10.1097/bcr.0000000000000142. PubMed PMID: 25127026; eng.

27. Smith KE, Brown CS, Manning BM, et al. Accuracy of Point-of-Care Blood Glucose Level Measurements in Critically III Patients with Sepsis Receiving High-Dose Intravenous Vitamin C. Pharmacotherapy. 2018 Nov;38(11):1155-1161. doi: 10.1002/phar.2182. PubMed PMID: 30230568; eng.

28. Ambade VN, Sharma YV, Somani BLJMJAFI. METHODS FOR ESTIMATION OF BLOOD GLUCOSE : A COMPARATIVE EVALUATION. 1998;54(2):131.

29. Mark DJB, Biochemistry MBEABPotlUo, Biology M. An enzymatic clinical chemistry laboratory experiment incorporating an introduction to mathematical method comparison techniques. 2010;32(4):246-249.

30. Deutsch JC. Ascorbic acid oxidation by hydrogen peroxide. Analytical biochemistry. 1998 Jan 1;255(1):1-7. doi: 10.1006/abio.1997.2293. PubMed PMID: 9448835; eng.

31. Howell AP, Parrett JL, Malcom DR. Impact of High-Dose Intravenous Vitamin C for Treatment of Sepsis on Point-of-Care Blood Glucose Readings. Journal of diabetes science and technology. 2019 Nov 25:1932296819889638. doi:

10.1177/1932296819889638. PubMed PMID: 31766883; eng.

32. Cho J, Ahn S, Yim J, et al. Influence of Vitamin C and Maltose on the Accuracy of Three Models of Glucose Meters. Annals of laboratory medicine. 2016 May;36(3):271-4. doi: 10.3343/alm.2016.36.3.271. PubMed PMID: 26915620; PubMed Central PMCID: PMCPMC4773272 interest relevant to this article were reported. eng.

33. Ma Y, Sullivan GG, Schrick E, et al. A convenient method for measuring blood ascorbate concentrations in patients receiving high-dose intravenous ascorbate. Journal of the American College of Nutrition. 2013;32(3):187-93. doi: 10.1080/07315724.2013.791167. PubMed PMID: 23885992; PubMed Central PMCID: PMCPMC3725640. eng.

34. Long CL, Maull KI, Krishnan RS, et al. Ascorbic acid dynamics in the seriously ill and injured. The Journal of surgical research. $2003 \mathrm{Feb;109(2):144-8.} \mathrm{doi:} \mathrm{10.1016/s0022-}$ 4804(02)00083-5. PubMed PMID: 12643856; eng. 
It is made available under a CC-BY-NC-ND 4.0 International license .

35. Oudemans-van Straaten HM, Spoelstra-de Man AM, de Waard MC. Vitamin C revisited. Critical care (London, England). 2014 Aug 6;18(4):460. doi: 10.1186/s13054-014-0460-x. PubMed PMID: 25185110; PubMed Central PMCID: PMCPMC4423646. eng.

36. Nathens AB, Neff MJ, Jurkovich GJ, et al. Randomized, prospective trial of antioxidant supplementation in critically ill surgical patients. Annals of surgery. 2002 Dec;236(6):814-22. doi: 10.1097/00000658-200212000-00014. PubMed PMID: 12454520; PubMed Central PMCID: PMCPMC1422648. eng.

37. Fowler AA, 3rd, Syed AA, Knowlson S, et al. Phase I safety trial of intravenous ascorbic acid in patients with severe sepsis. Journal of translational medicine. 2014 Jan 31;12:32. doi: 10.1186/1479-5876-12-32. PubMed PMID: 24484547; PubMed Central PMCID: PMCPMC3937164. eng.

38. Marik PE. Vitamin C for the treatment of sepsis: The scientific rationale. Pharmacology \& therapeutics. 2018 Sep;189:63-70. doi: 10.1016/j.pharmthera.2018.04.007. PubMed PMID: 29684467; eng.

39. Fowler AA, 3rd, Truwit JD, Hite RD, et al. Effect of Vitamin C Infusion on Organ Failure and Biomarkers of Inflammation and Vascular Injury in Patients With Sepsis and Severe Acute Respiratory Failure: The CITRIS-ALI Randomized Clinical Trial. Jama. 2019 Oct 1;322(13):1261-1270. doi: 10.1001/jama.2019.11825. PubMed PMID: 31573637; PubMed Central PMCID: PMCPMC6777268 Virginia Tech School of Medicine; grants from the National Heart, Lung, and Blood Institute (NHLBI); and study materials from McGuff Pharmaceuticals during the conduct of the study. Dr Truwit reports receiving grants from the National Institutes of Health $(\mathrm{NIH})$ during the conduct of the study. Dr Hite reports receiving grants from NHLBI during the conduct of the study, grants from the Marcus Foundation, and grants from NHLBI outside the submitted work. Dr Morris reports receiving grants from NIH during the conduct of the study. Dr Thacker reports receiving grants from NIH during the conduct of the study. Dr Brophy reports receiving grants from NIH during the conduct of the study. Dr Sturgill reports receiving grants from NIH during the conduct of the study. Dr Martin reports receiving grants from NHLBI during the conduct of the study. Dr Sevransky reports receiving grants from NIH during the conduct of the study and grants from the Marcus Foundation outside the submitted work. Ms Egan reports receiving grants from Emory University during the conduct of the study. Dr Duggal reports receiving grants from NIH during the conduct of the study. Ms Graf reports receiving grants from Virginia Commonwealth University during the conduct of the study. Ms Zellner reports receiving grants from Virginia Commonwealth University during the conduct of the study. Ms Yanny reports receiving grants from the Medical College of Wisconsin during the conduct of the study. Ms McPolin reports receiving grants from the Medical College of Wisconsin during the conduct of the study. Ms Hollrith reports receiving grants from the Medical College of Wisconsin during the conduct of the study. Dr Damm reports receiving grants from the Medical College of Wisconsin during the conduct of the study. Mr Cassity reports receiving grants from NIH during the conduct of the study. No other disclosures were reported. eng.

40. Nielsen TK, Højgaard M, Andersen JT, et al. Elimination of ascorbic acid after high-dose infusion in prostate cancer patients: a pharmacokinetic evaluation. Basic \& clinical pharmacology \& toxicology. 2015 Apr;116(4):343-8. doi: 10.1111/bcpt.12323. PubMed PMID: 25220574; eng. 
medRxiv preprint doi: https://doi.org/10.1101/2020.11.23.20237461; this version posted November 24, 2020. The copyright holder for this preprint (which was not certified by peer review) is the author/funder, who has granted medRxiv a license to display the preprint in perpetuity.

It is made available under a CC-BY-NC-ND 4.0 International license .

Table 1. Characteristics of the 82 patients with VC therapy

\begin{tabular}{|c|c|}
\hline Characteristics & $\begin{array}{l}\text { Data } \\
n=82\end{array}$ \\
\hline Age (y) & $55(41.75-69)$ \\
\hline Male & $59(71.95)$ \\
\hline Height $(\mathrm{cm})$ & $170(165-175)$ \\
\hline Weight (kg) & $70(61.5-80)$ \\
\hline History of diabetes mellitus & $15(18.29)$ \\
\hline History of chronic kidney diseases & $7(8.54)$ \\
\hline Serum creatine $(\mu \mathrm{mol} / \mathrm{L})$ & $82.5(63-149.25)$ \\
\hline \multicolumn{2}{|l|}{ Renal Function } \\
\hline Non-impaired renal function & $42(51.22)$ \\
\hline Impaired renal function & $16(19.51)$ \\
\hline $\mathrm{ARC}$ & $9(10.98)$ \\
\hline CRRT & $15(18.29)$ \\
\hline CVVH & $1(1.22)$ \\
\hline CVVHD & $4(4.88)$ \\
\hline CVVHDF & $10(12.20)$ \\
\hline Hemoglobin $(\mathrm{g} / \mathrm{L})$ & $114(85-136.5)$ \\
\hline Hematocrit between $10-65 \%$ & $82(100)$ \\
\hline APACHE II score & $14(12-20)$ \\
\hline SIRS score & $3(2-3)$ \\
\hline VC daily dosage $[\mathrm{mg} /(\mathrm{kg} \bullet \mathrm{d})]$ & $100(74.99-133.33)$ \\
\hline Lower dosage & $47(57.32)$ \\
\hline Higher dosage & $35(42.68)$ \\
\hline VC therapy duration (d) & $9(6-15)$ \\
\hline Clinical Outcome & $82(100)$ \\
\hline Cure & $5(6.10)$ \\
\hline Recovery & $52(63.41)$ \\
\hline Exacerbation & $9(10.98)$ \\
\hline Death & $16(19.51)$ \\
\hline
\end{tabular}

Data are median (interquartile range, IQR) values or no. (\%) of patients. 
medRxiv preprint doi: https://doi.org/10.1101/2020.11.23.20237461; this version posted November 24, 2020. The copyright holder for this preprint (which was not certified by peer review) is the author/funder, who has granted medRxiv a license to display the preprint in perpetuity.

It is made available under a CC-BY-NC-ND 4.0 International license .

APACHE = Acute Physiology and Chronic Health Evaluation .

SIRS =Systemic Inflammatory Response Syndrome.

Table 2. Statistical analysis among all POCG and LG paired values before and after VC treatment

\begin{tabular}{cccc}
\hline & Before VC Treatment & After VC Treatment & $P$-value \\
\hline POCG $(\mathrm{mg} / \mathrm{dl})$ & $158.08(62.08)$ & $142.90(58.91)$ & $<0.001^{*}$ \\
LG $(\mathrm{mg} / \mathrm{dl})$ & $186.25(71.50)$ & $186.74(72.74)$ & $<0.001^{\#}$ \\
Relative Difference Percentage (\%) & $-12.43(21.44)$ & $-17.86(35.68)$ & $0.01^{\bullet}$ \\
\hline
\end{tabular}

Data expressed as mean (standard deviation of the mean).

*This P-value stands for the difference between POCG reading before VC treatment and POCG reading after VC treatment.

${ }^{\text {\# } T h i s ~} P$-value stands for the difference between $L G$ reading before $V C$ treatment and $L G$ reading after

VC treatment.

-This P-value stands for the difference between Relative Difference Percentage before VC treatment and

Relative Difference Percentage after VC treatment. 
medRxiv preprint doi: https://doi.org/10.1101/2020.11.23.20237461; this version posted November 24, 2020. The copyright holder for this preprint (which was not certified by peer review) is the author/funder, who has granted medRxiv a license to display the preprint in perpetuity.

It is made available under a CC-BY-NC-ND 4.0 International license .

Table 3. Difference of POCG compared to LG for all paired glucose values by ISO 15197:2013 criteria range

\begin{tabular}{cc}
\hline ISO $15197: 2013$ criteria range* & $\mathrm{n}=82(\%)$ \\
\hline$\leq 5 \%$ or $5 \mathrm{mg} / \mathrm{dl}^{\#}$ & $8(9.76)$ \\
$>5-10 \%$ or $6-10 \mathrm{mg} / \mathrm{dl}^{\#}$ & $9(10.98)$ \\
$>10-15 \%$ or $11-15 \mathrm{mg} / \mathrm{dl}^{\#}$ & $13(15.85)$ \\
$>15-20 \%$ or $16-20 \mathrm{mg} / \mathrm{dl}$ & $5(6.10)$ \\
$>20 \%$ or $21 \mathrm{mg} / \mathrm{dl}$ & $47(57.31)$ \\
\hline
\end{tabular}

*International Organization of Standardization (ISO); ISO 15197:2013 criteria: blood glucose

measurement result need to be in range of $\pm 15 \mathrm{mg} / \mathrm{dl}$ when referential blood glucose result is less than

$100 \mathrm{mg} / \mathrm{dl}$, or within $\pm 15 \%$ of the referential blood glucose result if the blood glucose level is no less

than $100 \mathrm{mg} / \mathrm{dl}$.

${ }^{\#}$ In compliance of ISO 15197:2013 criteria. 
Table 4. Subgroup Analysis for various dosage about difference of POCG compared to LG for all paired glucose values by ISO 15197:2013 criteria range

\begin{tabular}{ccc}
\hline ISO $15197: 2013$ criteria range* & $\begin{array}{c}\text { Lower Dosage } \\
\mathrm{n}=47(\%)\end{array}$ & $\begin{array}{c}\text { Higher Dosage } \\
\mathrm{n}=35(\%)\end{array}$ \\
\hline$\leq 5 \%$ or $5 \mathrm{mg} / \mathrm{dl}{ }^{\#}$ & $5(10.64)$ & $3(8.57)$ \\
$>5-10 \%$ or $6-10 \mathrm{mg} / \mathrm{dl}^{\#}$ & $5(10.64)$ & $4(11.43)$ \\
$>10-15 \%$ or $11-15 \mathrm{mg} / \mathrm{dl}^{\#}$ & $8(17.02)$ & $5(14.29)$ \\
$>15-20 \%$ or $16-20 \mathrm{mg} / \mathrm{dl}$ & $4(8.51)$ & $1(2.86)$ \\
$>20 \%$ or $21 \mathrm{mg} / \mathrm{dl}$ & $25(53.19)$ & $22(62.86)$ \\
\hline *International Organization of Standardization (ISO); ISO 15197:2013 criteria: blood glucose \\
measurement result need to be in range of \pm 15 mg/dl when referential blood glucose result is less than \\
100 mg/dl, or within $\pm 15 \%$ of the referential blood glucose result if the blood glucose level is no less \\
than 100 mg/dl. \\
\#In compliance of ISO 15197:2013 criteria.
\end{tabular}


Table 5. The Parkes Consensus Error Grid Analysis for POCG values compared to LG readings for various dosage groups

\begin{tabular}{ccc}
\hline & \multicolumn{2}{c}{ Number of pairs (\%) } \\
\cline { 2 - 3 } Zone* & Lower Dosage & Higher Dosage \\
$\mathrm{n}=47(\%)$ & $\mathrm{n}=35(\%)$ \\
$\mathrm{A}$ & $26(55.32)$ & $16(45.71)$ \\
$\mathrm{B}$ & $10(21.28)$ & $9(25.71)$ \\
$\mathrm{C}$ & $11(23.40)$ & $8(22.86)$ \\
$\mathrm{D}$ & 0 & $2(5.71)$ \\
$\mathrm{E}$ & 0 & 0 \\
\hline
\end{tabular}

* This error grid was divided into 5 zones which symbolized corresponding degree of risk associated with inaccurate measurement results. Zone A meant difference had no effect on clinical action. Zone B represented altering clinical action that could change little or no effect on clinical outcome. Zone $C$ signified altering clinical action that could be likely to affect clinical outcome. Zone D was known as altering clinical action that could cause significant medical risk and Zone E defined clinical actions that could have dangerous consequences. 
Table 6. Subgroup Analysis for diverse renal function about difference of POCG compared to LG for all paired glucose values by ISO 15197:2013 criteria range

\begin{tabular}{ccccc}
\hline ISO 15197:2013 criteria range* & $\begin{array}{c}\text { Non-impaired } \\
\text { renal function } \\
\mathrm{n}=42(\%)\end{array}$ & $\begin{array}{c}\text { Impaired } \\
\text { renal function } \\
\mathrm{n}=16(\%)\end{array}$ & $\begin{array}{c}\mathrm{ARC} \\
\mathrm{n}=9(\%)\end{array}$ & $\begin{array}{c}\mathrm{CRRT}^{\bullet} \\
\mathrm{n}=15(\%)\end{array}$ \\
\hline$\leq 5 \%$ or $5 \mathrm{mg} / \mathrm{dl}^{\#}$ & $5(11.90)$ & $1(6.25)$ & 0 & $2(13.33)$ \\
$>5-10 \%$ or $6-10 \mathrm{mg} / \mathrm{dl}^{\#}$ & $8(19.05)$ & $1(6.25)$ & 0 & 0 \\
$>10-15 \%$ or $11-15 \mathrm{mg} / \mathrm{dl}^{\#}$ & $6(14.29)$ & $4(25)$ & $2(22.22)$ & $1(6.67)$ \\
$>15-20 \%$ or $16-20 \mathrm{mg} / \mathrm{dl}$ & $2(4.76)$ & $1(6.25)$ & 0 & $2(13.33)$ \\
$>20 \%$ or $21 \mathrm{mg} / \mathrm{dl}$ & $21(50)$ & $9(56.25)$ & $7(77.78)$ & $10(66.67)$ \\
\hline
\end{tabular}

*International Organization of Standardization (ISO); ISO 15197:2013 criteria: blood glucose measurement result need to be in range of $\pm 15 \mathrm{mg} / \mathrm{dl}$ when referential blood glucose result is less than $100 \mathrm{mg} / \mathrm{dl}$, or within $\pm 15 \%$ of the referential blood glucose result if the blood glucose level is no less than $100 \mathrm{mg} / \mathrm{dl}$.

${ }^{\#}$ In compliance of ISO 15197:2013 criteria.

-ARC: Augmented Renal Clearance.

${ }^{\square}$ CRRT: Continuous Renal Replacement Therapy. 
Table 7. The Parkes Consensus Error Grid Analysis for POCG values compared to LG readings for groups of different renal function level

\begin{tabular}{ccccc}
\hline & \multicolumn{4}{c}{ Number of pairs (\%) } \\
\cline { 2 - 5 } Zone* & $\begin{array}{c}\text { Non-impaired } \\
\text { renal function } \\
\mathrm{n}=42(\%)\end{array}$ & $\begin{array}{c}\text { Impaired } \\
\text { renal function } \\
\mathrm{n}=16(\%)\end{array}$ & $\begin{array}{c}\text { ARC } \\
\mathrm{n}=9(\%)\end{array}$ & $\begin{array}{c}\text { CRRT } \\
\mathrm{n}=15(\%)\end{array}$ \\
\hline $\mathrm{A}$ & $27(64.29)$ & $8(50)$ & $3(33.33)$ & $4(26.67)$ \\
$\mathrm{B}$ & $6(14.29)$ & $3(18.75)$ & $5(55.56)$ & $5(33.33)$ \\
$\mathrm{C}$ & $9(21.43)$ & $4(25)$ & $1(11.11)$ & $5(33.33)$ \\
$\mathrm{D}$ & 0 & $1(6.25)$ & 0 & $1(6.67)$ \\
$\mathrm{E}$ & 0 & 0 & 0 & 0 \\
\hline
\end{tabular}

* This error grid was divided into 5 zones which symbolized corresponding degree of risk associated with inaccurate measurement results. Zone A meant difference had no effect on clinical action. Zone B represented altering clinical action that could change little or no effect on clinical outcome. Zone C signified altering clinical action that could be likely to affect clinical outcome. Zone D was known as altering clinical action that could cause significant medical risk and Zone E defined clinical actions that could have dangerous consequences. 
medRxiv preprint doi: https://doi.org/10.1101/2020.11.23.20237461; this version posted November 24, 2020. The copyright holder for this preprint (which was not certified by peer review) is the author/funder, who has granted medRxiv a license to display the preprint in perpetuity.

It is made available under a CC-BY-NC-ND 4.0 International license .

Fig. 1 Comparison between POCG and reference LG levels by Bland-Altman plot.

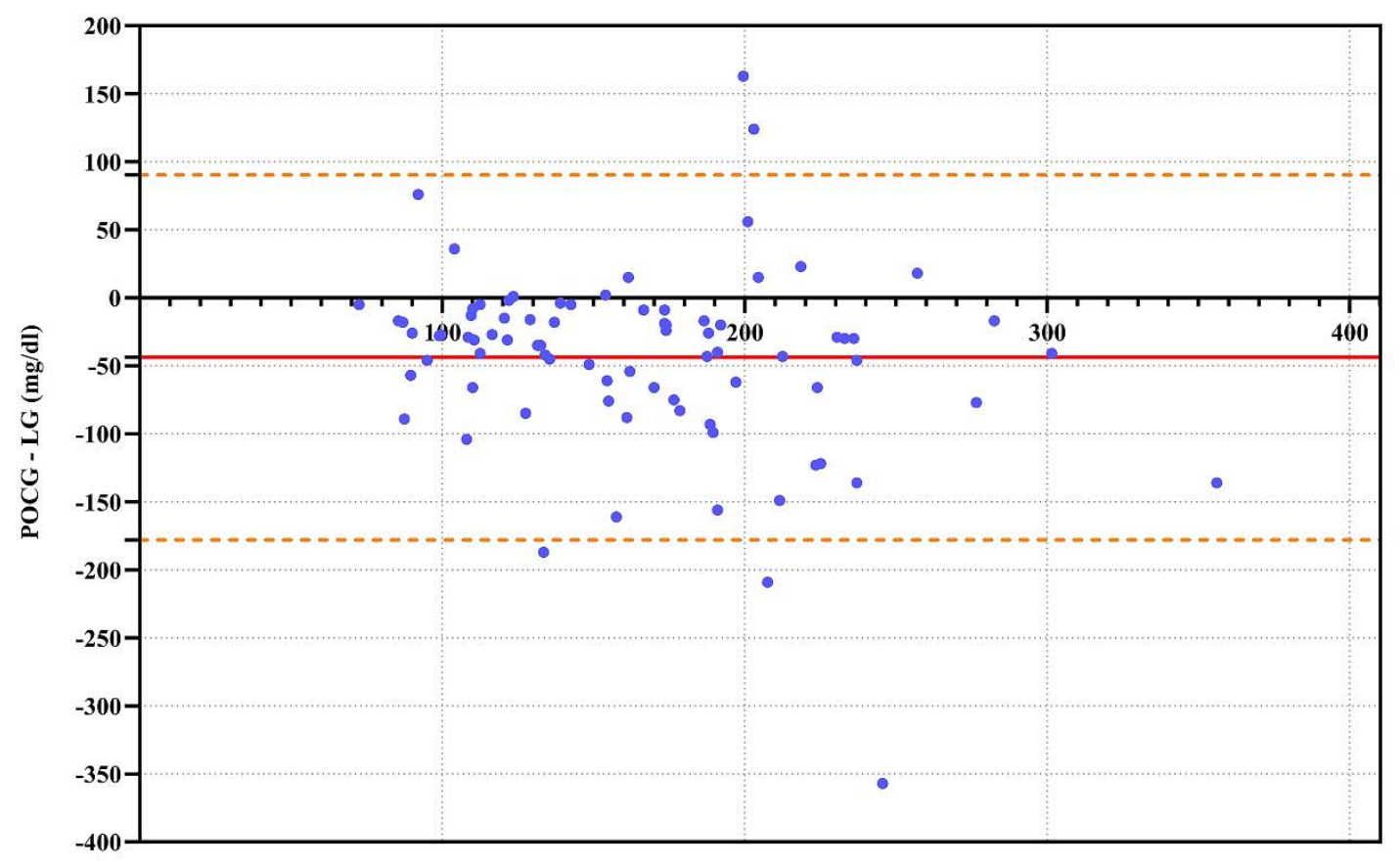

Average of POCG and LG (mg/dl)

The red solid line means the mean difference among all paired data, namely bias. The orange dashed lines represent the $95 \%$ limits of agreement. 
medRxiv preprint doi: https://doi.org/10.1101/2020.11.23.20237461; this version posted November 24, 2020. The copyright holder for this preprint (which was not certified by peer review) is the author/funder, who has granted medRxiv a license to display the preprint in perpetuity.

It is made available under a CC-BY-NC-ND 4.0 International license .

Fig. 2 The Parkes Consensus Error Grid Analysis of paired blood glucose readings between POCG and LG.

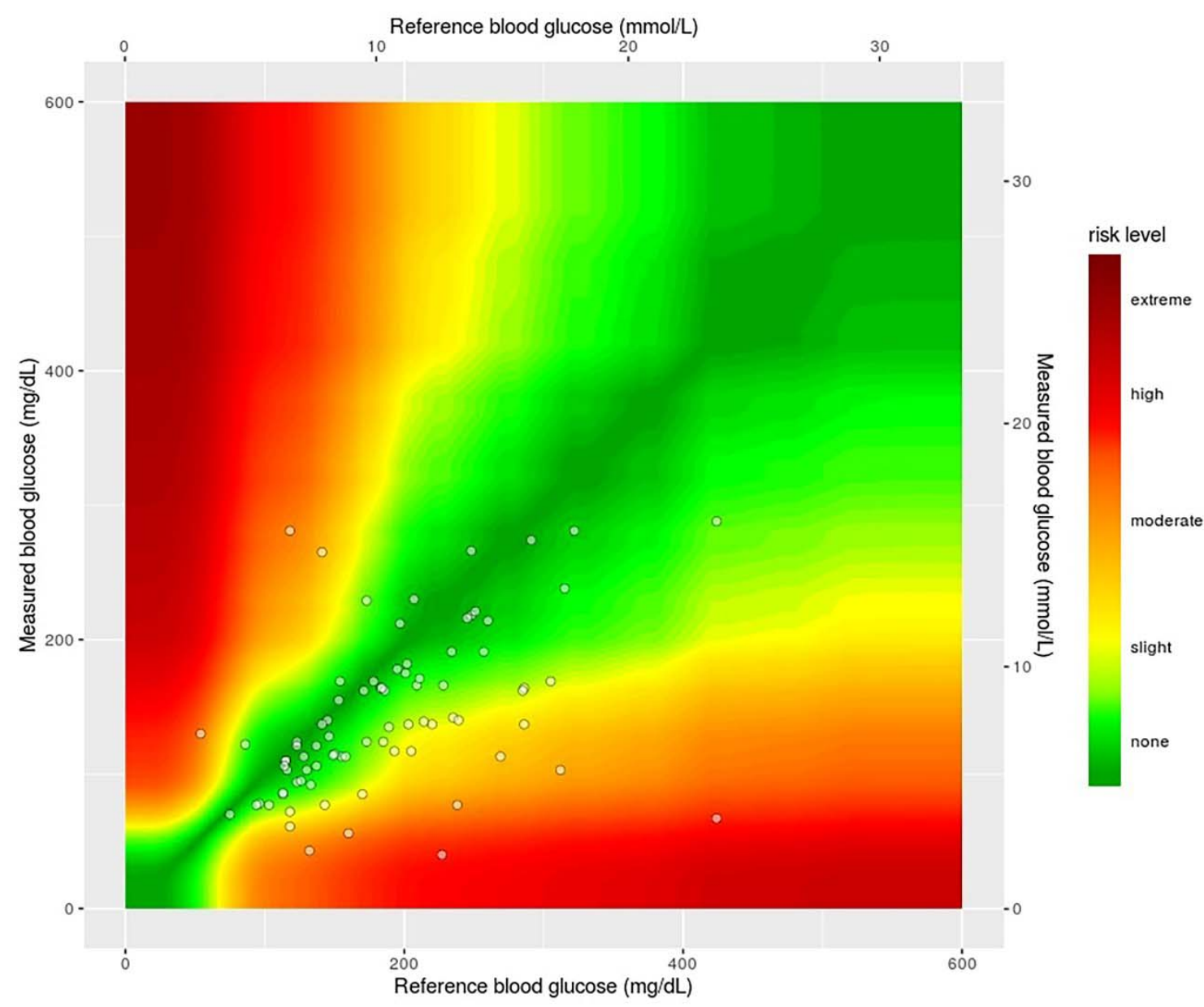

This error grid was divided into 5 zones which symbolized corresponding degree of risk associated with inaccurate measurement results. Zone A meant difference had no effect on clinical action. Zone B represented altering clinical action that could change little or no effect on clinical outcome. Zone C signified altering clinical action that could be likely to affect clinical outcome. Zone D was known as altering clinical action that could cause significant medical risk and Zone E defined clinical actions that could have dangerous consequences. 
Fig. 3 Three kinds of blood glucose monitoring methods: hexokinase spectrophotometric method (a); glucose oxidase-peroxidase (GOD-POD) colorimetric method (b); glucose dehydrogenase pyrroloquinoline quinone (GDH-PQQ) amperometric method (c).

\section{(a)}

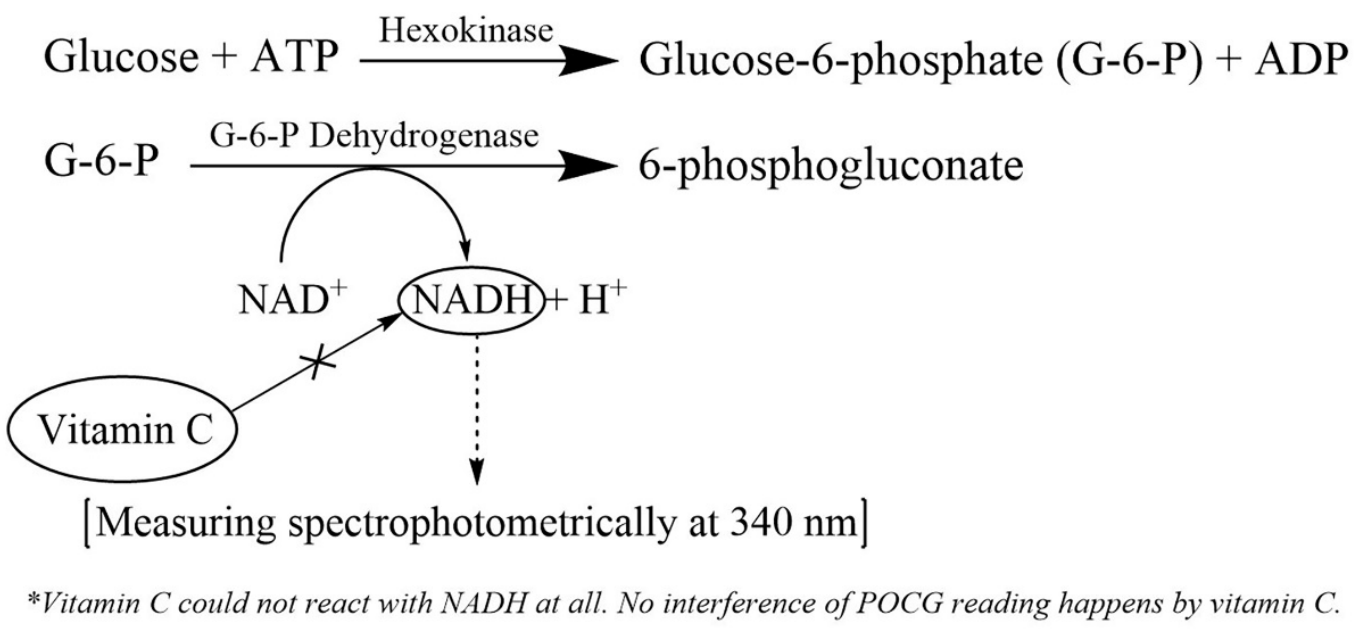

\section{(b)}

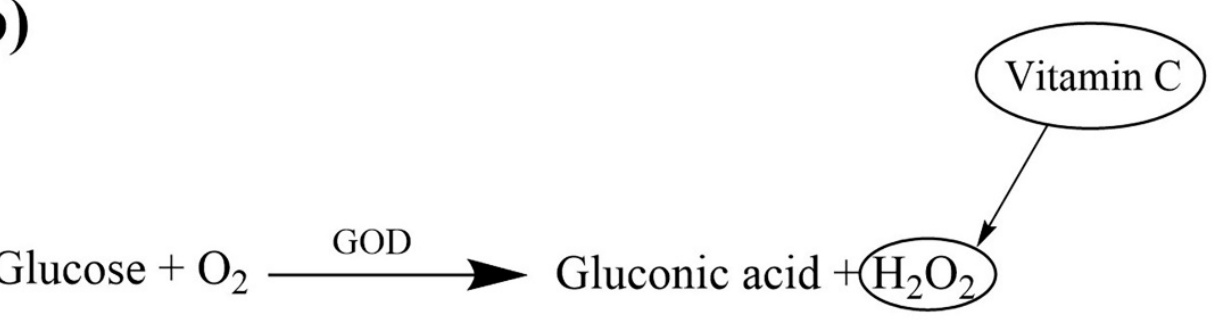

4-aminophenazone + Phenol $+\mathrm{H}_{2} \mathrm{O}_{2} \stackrel{\mathrm{POD}}{\longrightarrow}$ Quinonimine $+\mathrm{H}_{2} \mathrm{O}$

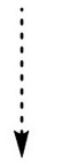

[Measuring colorimetrically at $530 \mathrm{~nm}$ ]

*Depletion of $\mathrm{H}_{2} \mathrm{O}_{2}$ is caused by redox reaction with Vitamin $\mathrm{C}$, which may lower POCG readings.

(c)

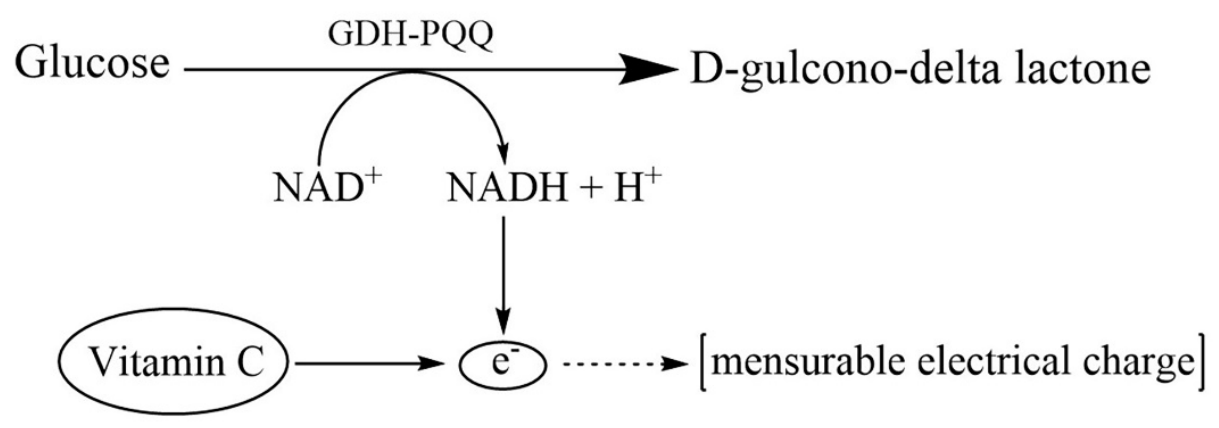

*Vitamin C creates extra eletrons at the electrode by its reducibility, which may elevate POCG readings. 


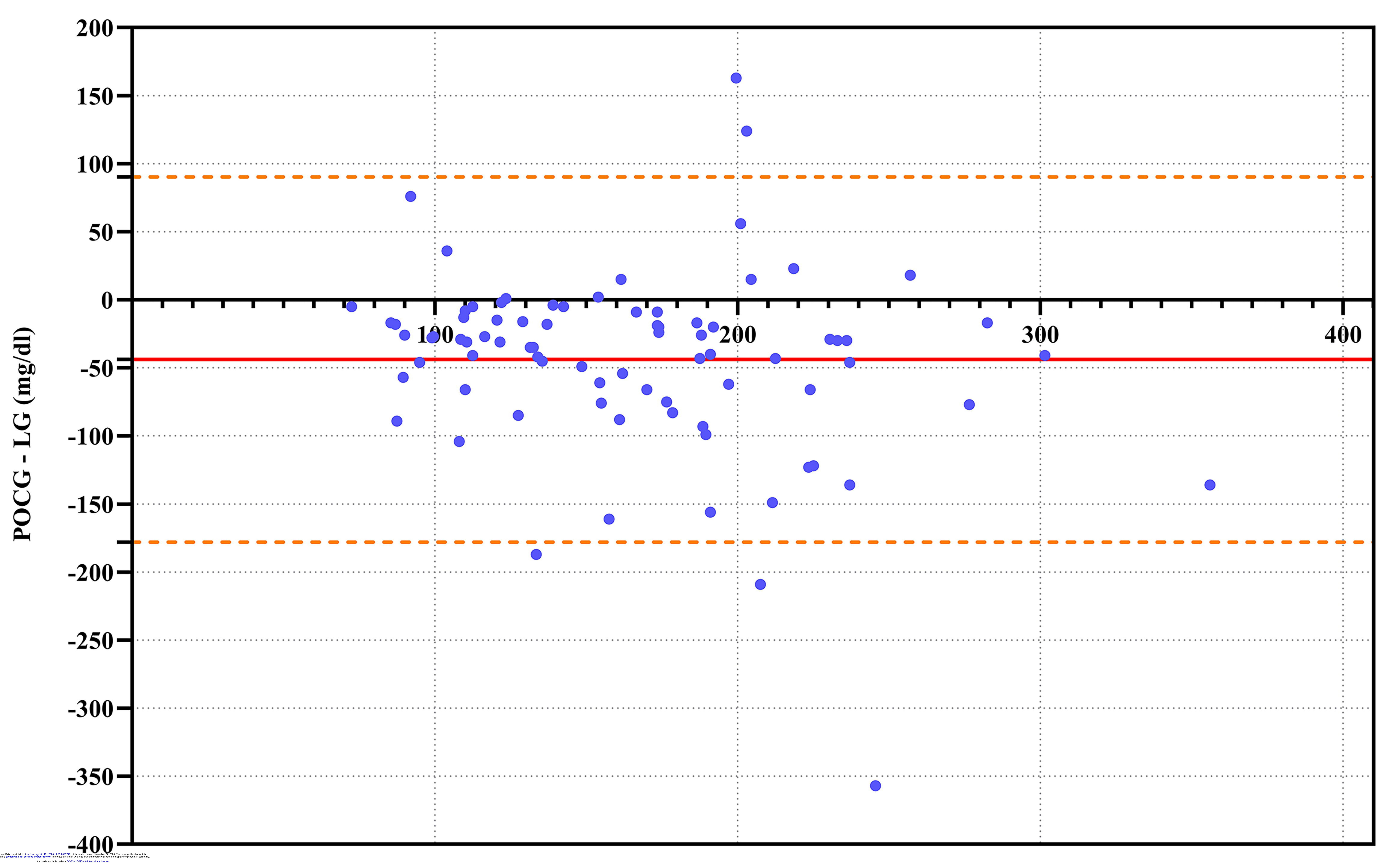

Average of POCG and LG (mg/dl)

The red solid line means the mean difference among all paired data, namely bias. The orange dashed lines represent the $95 \%$ limits of agreement. 


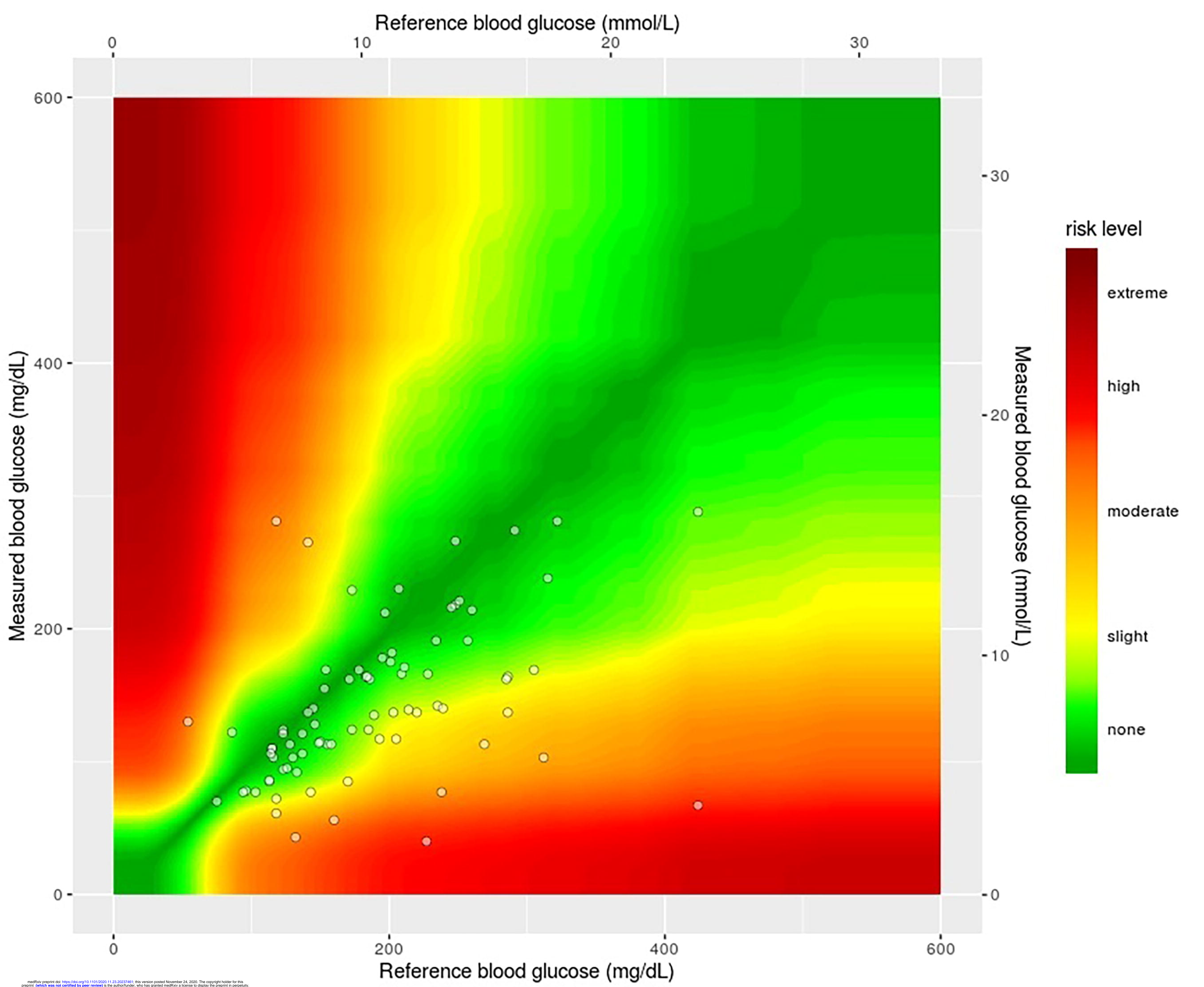

This error grid was divided into 5 zones which symbolized corresponding degree of risk associated with inaccurate measurement results. Zone A meant difference had no effect on clinical action. Zone B represented altering clinical action that could change little or no effect on clinical outcome. Zone C signified altering clinical action that could be likely to affect clinical outcome. Zone D was known as altering clinical action that could cause significant medical risk and Zone E defined clinical actions that could have dangerous consequences. 


\section{Glucose + ATP $\stackrel{\text { Hexokinase }}{\longrightarrow}$ Glucose-6-phosphate (G-6-P) + ADP}

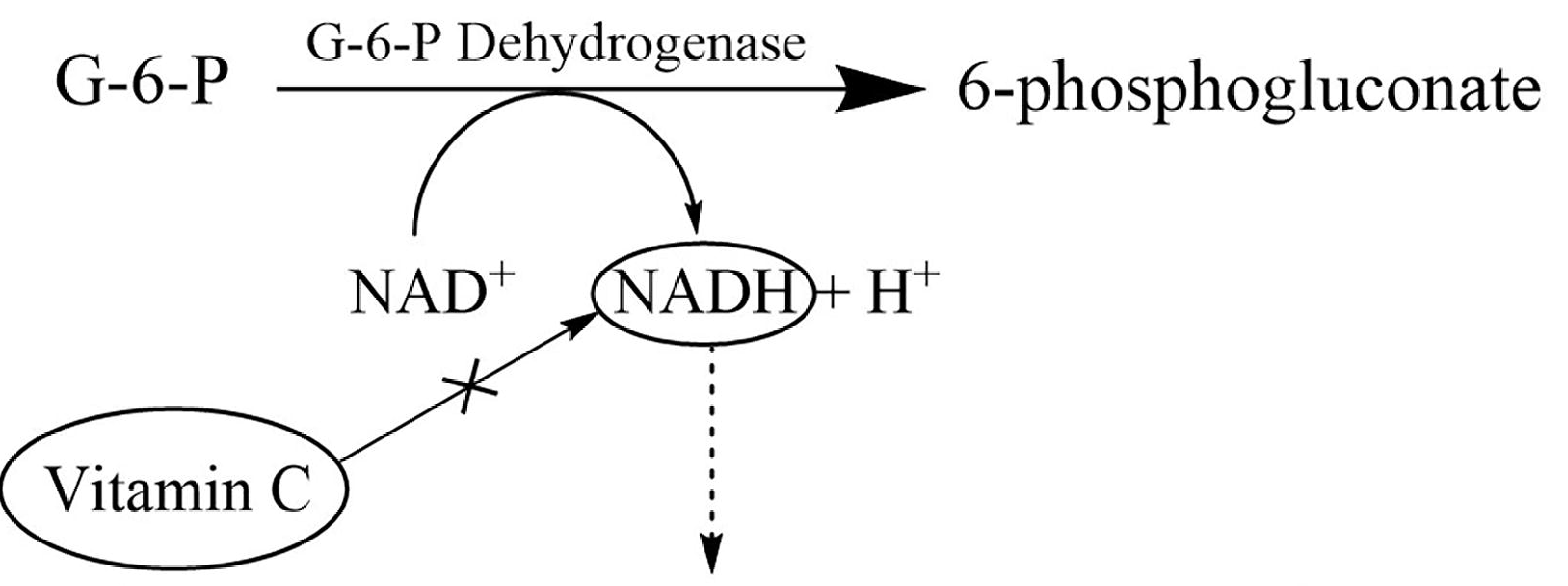

[Measuring spectrophotometrically at $340 \mathrm{~nm}$ ]

*Vitamin $C$ could not react with NADH at all. No interference of POCG reading happens by vitamin C.

\section{(b)}

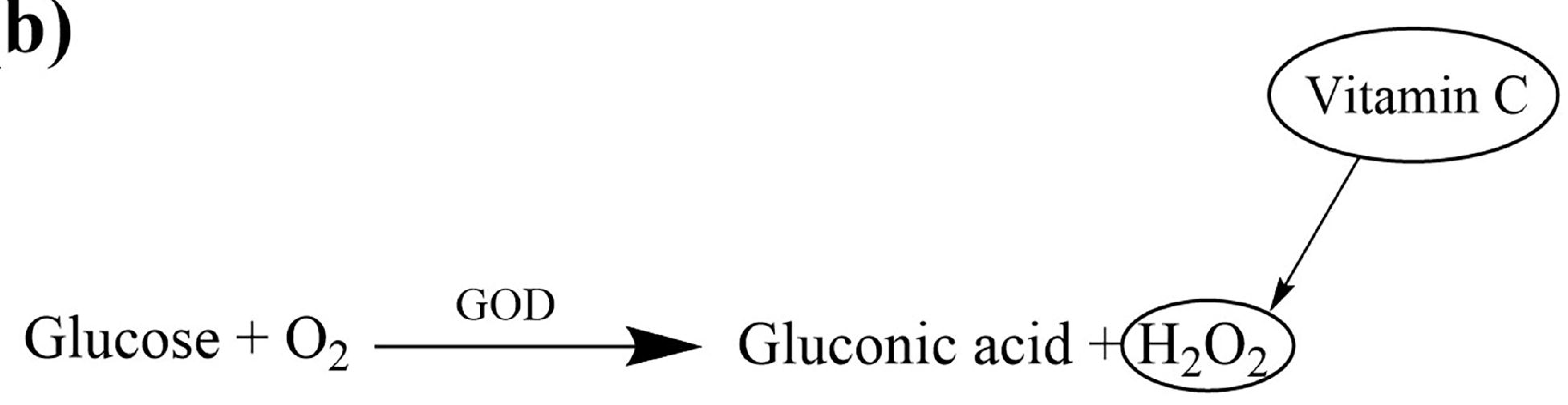

4-aminophenazone + Phenol $+\mathrm{H}_{2} \mathrm{O}_{2} \stackrel{\mathrm{POD}}{\longrightarrow}$ Quinonimine $+\mathrm{H}_{2} \mathrm{O}$

[Measuring colorimetrically at $530 \mathrm{~nm}$ ]

*Depletion of $\mathrm{H}_{2} \mathrm{O}_{2}$ is caused by redox reaction with Vitamin $C$, which may lower POCG readings.

\section{(c)}

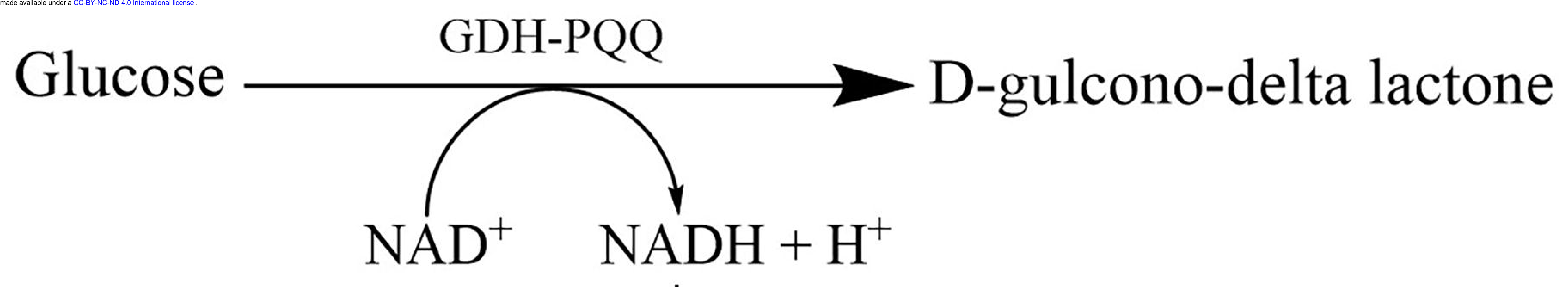

Vitamin C

*Vitamin $C$ creates extra eletrons at the electrode by its reducibility, which may elevate POCG readings. 